\title{
Structure of Poly(vinyl alcohol)-Iodine Complex in Water Swollen Film
}

\author{
Yushi Oishi, Hiroshi Yamamoto, and Keizo MiYasaKa \\ Department of Textile and Polymeric Materials, Tokyo Institute \\ of Technology, Ookayama, Meguro-ku, Tokyo 152, Japan
}

(Received April 1, 1987)

\begin{abstract}
The structure of a poly(vinyl alcohol) (PVA)-iodine complex was investigated by a resonance Raman spectroscopy, wide angle X-ray diffraction, small angle X-ray scattering, NMR and IR spectroscopies. The Raman spectra of swollen PVA films exhibited fundamental scattering at 164,108 , and $42 \mathrm{~cm}^{-1}$ with $\mathrm{Ar}^{+}$ion and dye lasers as the excitation sources. The results of Raman spectra showed that only the $\mathrm{I}_{5}{ }^{-}$is formed in the complex, irrespective of the difference in the visible absorption spectra. The relative intensity of the peak at $65 \mathrm{ppm}$ decreased with increasing amount of complex in the ${ }^{13} \mathrm{C}$ NMR spectra. The absorbance of the infrared spectrum in the region of $2900-3300 \mathrm{~cm}^{-1}$ decreased with increased iodine concentration of the soaking solution, while the absorbance in the region of $3300-3700 \mathrm{~cm}^{-1}$ increased. These results show that some changes in the state of hydrogen bondings are induced by complexation. The weight of the PVA film increased rapidly by iodine sorption at the first stage and then decreased. The changes of the long period and volume took place rapidly, being followed by much slower increase in Young's modulus. The ratio of the decrease in volume was much larger than that of the long period. It was assumed that the fast contraction in iodine-soaking was mainly due to the release of water out of membranes induced by iodine-sorption but not due to the complexation.
\end{abstract}

KEY WORDS Iodine-Poly(vinyl alcohol) Complex / Poly(vinyl alcohol) /

Resonance Raman Spectroscopy / Wide Angle X-Ray Diffraction / Small

Angle X-Ray Scattering / NMR / IR / Hydrogen Bond / Polyiodine /

The blue PVA-iodine complex has already been studied by many authors. X-ray diffraction studies ${ }^{1}$ reveal that straight polyiodine chains of a $3.1 \AA$ periodicity lie parallel to the orientation direction of PVA. The number of iodine atoms in a polyiodine chain, however, depends on the researchers. Haisa et al. ${ }^{2}$ proposed that the polyiodine chains are made of more than 15 iodine atoms on the basis of the width of an X-ray diffraction. Heyde et al. ${ }^{3}$ and lnagaki et al. ${ }^{4}$ found that the resonance Raman spectrum of the PVA-iodine complex formed in the solution was similar to that of the amylose-iodine complex, and assumed that $\mathrm{I}_{3}{ }^{-}$was formed in the PVA-iodine complex. Later however it was confirmed by Teitelbaum ${ }^{5}$ that $\mathrm{I}_{5}{ }^{-}$is still formed in the amylose-iodine complex.
In a previous paper, ${ }^{6}$ it was shown that under a given soaking condition, $\lambda_{\max }$ shifts continuously from 525 to $610 \mathrm{~nm}$ with increasing degree of hydration, DH and decreasing temperature. Kojima et al. ${ }^{7}$ observed that $\lambda_{\max }$ shifts continuously from 620 to $700 \mathrm{~nm}$ with extension of PVA films. Zwick ${ }^{8}$ reported that in a PVA solution, $\lambda_{\max }$ shifts continuously from 580 to $700 \mathrm{~nm}$ with increasing concentration of boric acid added to the iodine and PVA solution. It is believed that the red shift of $\lambda_{\max }$ is due to the increased number of iodine atoms in polyiodine chains. Only ambiguous explanations, however, have been given to this problem.

There have been many discussions about the structure of PVA chains in the complex. A helical model ${ }^{4,8}$ and an aggregation model ${ }^{9,10}$ 
are proposed for the structure of the PVAiodine complex. We observed an enhancement of the complexation by extension of a PVA film on soaking in a dilute iodine solution. ${ }^{11}$ This seems to support the aggregation model for the PVA-iodine complex. Terao et al. ${ }^{12}$ studied the state of hydrogen bonds and tacticity of PVA by high-resolution solid-state ${ }^{13} \mathrm{C}$ NMR, implying the usefulness of the method for the study of the complex structure.

In this paper, the structure of the complex is studied in relation to the chain conformation of PVA and polyiodine chain, using a resonance Raman spectroscopy, wide angle $\mathrm{X}$ ray diffraction, high-resolution solid-state ${ }^{13} \mathrm{C}$ NMR and Fourier transform infrared spectroscopy FT-IR. The effect of the superstructure of PVA films on the complexation is also examined by small angle $\mathrm{X}$-ray scattering.

\section{EXPERIMENTAL}

The preparation methods of PVA films and iodine aqueous solutions were the same as those described in a previous paper, ${ }^{6}$ PVA $(\mathrm{DP}=2000)$ was used after being saponified further with sodium methoxide in $\mathrm{MeOH}$. Films $100 \mu \mathrm{m}$ thick were cast at room temperature from a $7 \mathrm{wt} \%$ aqueous PVA solution, followed by annealing to get different DHs of the specimens. The DH was defined as the volume fraction of water in a PVA film at the equilibrium swollen state. The concentration of iodine in the solution varied from $5 \times 10^{-4}$ to $1 \times 10^{-1} \mathrm{~mol} \mathrm{l}^{-1}$.

The Raman spectra were obtained by a Nippon Denshi 400D Raman spectrophotometer. The $514.5 \mathrm{~nm}$ line of an argon ion laser and $600.0 \mathrm{~nm}$ line of a rhodamine $6 \mathrm{G}$ dye laser were used as the excitation sources. To prevent damage to the samples due to irradiation of the laser beam, 50 milliwatts of power were used and the samples were rotated at $1500 \mathrm{rpm}$. For an oriented sample, the laser beam was defocused to reduce cross-sectional power density. Spectra were obtained at a resolution of $5 \mathrm{~cm}^{-1}$ and a $90^{\circ}$ scattering geometry.

A stabilized generator (Rigaku Rotaflex RU200) operating at $50 \mathrm{kV}-180 \mathrm{~mA}$ was used as the $\mathrm{X}$-ray source. Wide and small angle $\mathrm{X}$ ray measurements were carried out by a transmission method using a Rigaku SG-7 and a Rigaku Model-1 goniometers, respectively. The SAXS intensity was desmeared using the following equation ${ }^{13}$

$$
I(S)=-\frac{\exp \left(p^{2} S^{2}\right)}{p \pi^{1 / 2}} \int_{0}^{\infty} \frac{N^{\prime}\left[\left(S^{2}+t^{2}\right)^{1 / 2}\right] \mathrm{d} t}{\left(S^{2}+t^{2}\right)^{1 / 2}}
$$

where $S$ is a scattering angle and $N(S)=$ $I(S) \exp \left(-p^{2} S^{2}\right)$.

Solid-state ${ }^{13} \mathrm{C}$ NMR spectra were obtained by a Nippon Denshi GX-270 spectrometer operating at $67.9 \mathrm{MHz}$ for ${ }^{13} \mathrm{C}$ using the crosspolarization technique (CP) with high-power proton decoupling and magic-angle spinning (MAS). The contact time was $2.0 \mathrm{~ms}$ and a repetition period was $5.0 \mathrm{~s}$. CP/MAS spectra were obtained at a spinning frequency of $3.5 \mathrm{kHz} .{ }^{13} \mathrm{C}$ chemical shifts are shown in parts per million (ppm) relative to that of $\mathrm{Me}_{4} \mathrm{Si}$.

For measuring infrared spectra, films about $2-3 \mu \mathrm{m}$ thick were cast, followed by annealing at $170^{\circ} \mathrm{C}$ to get a low DH specimen. IR spectra were recorded on a JASCO FT/IR-3 spectrophotometer.

Strips $4 \mathrm{~cm}$ long and $5 \mathrm{~mm}$ wide cut from the films were soaked in at an iodine concentration of $5 \times 10^{-2} \mathrm{~mol}^{-1}$ and stretched at a rate of $2.3 \mathrm{~mm} \mathrm{~min} .^{-1}$ The extension force was measured with a strain gauge, and then standardized by the cross-sectional area of the swollen films. Young's modulus was estimated from the slope.

\section{RESULTS AND DISCUSSION}

Swollen PVA films of $\mathrm{DH}=0.87$ were soaked in iodine solutions of $1-4 \times 10^{-3} \mathrm{~mol} \mathrm{l}^{-1}$ for 24 hours to form the complex. The resonance Raman spectra of these wet specimens obtained with the $514.5 \mathrm{~nm}$ line of an $\mathrm{Ar}^{+}$ion 


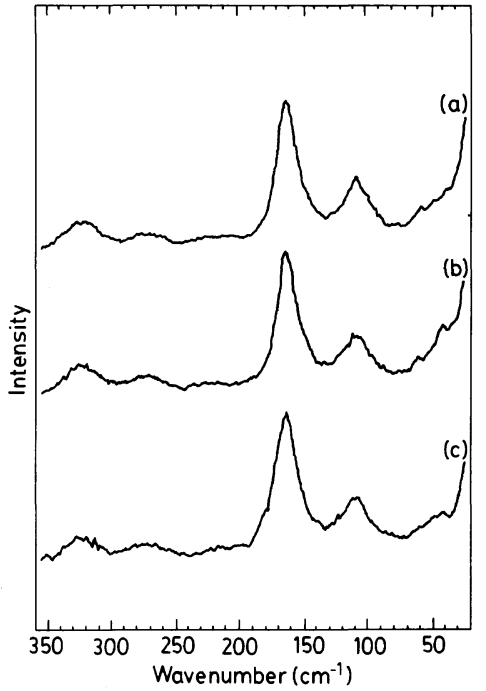

Figure 1. The resonance Raman spectra ( $\left.v_{0} 514.5 \mathrm{~nm}\right)$ of swollen PVA films soaked at various concentrations of iodine solution: (a) $1 \times 10^{-3} \mathrm{moll}^{-1}$; (b) $2 \times 10^{-3}$ moll ${ }^{-1}$; (c) $4 \times 10^{-3} \mathrm{moll}^{-1}$.

laser are shown in Figure 1. Their spectra exhibit strong scattering at $164 \mathrm{~cm}^{-1}$ and weaker ones at 108 and $42 \mathrm{~cm}^{-1}$. In addition, the overtone bands at 108 and $164 \mathrm{~cm}^{-1}$ obviously appear at 213 and $322 \mathrm{~cm}^{-1}$, respectively. The appearance of the combination band at $275 \mathrm{~cm}^{-1}$ may be evidence that the 164 and $108 \mathrm{~cm}^{-1}$ bands are due to fundamental transitions of the same iodine species. An intense transition at around $160 \mathrm{~cm}^{-1}$ has been found in compounds containing $\mathrm{I}_{5}{ }^{-}$species. ${ }^{14-16}$ The Raman active frequency of this transition varies depending on the $\mathrm{I}_{5}{ }^{-}$symmetry. For a symmetric and linear $\mathrm{I}_{5}{ }^{-}$ion, a strong band appears at $162 \mathrm{~cm}^{-1,14}$ while the frequency shifts to a higher value for distorted $\mathrm{I}_{5}{ }^{-}$species, formed by interactions between $\mathrm{I}_{2}$ and $\mathrm{I}_{3}{ }^{-}$. The latter Type of $\mathrm{I}_{2} / \mathrm{I}_{3}{ }^{-}$interactive units gives rise to vibrational transitions at
$167 \mathrm{~cm}^{-1}$ in (benzophenone) $)_{9}(\mathrm{KI})_{2} \mathrm{I}_{7} \mathrm{CH}$. $\mathrm{Cl}_{3},{ }^{15}$ and at $175 \mathrm{~cm}^{-1}$ in the $2 \cdot$ perylene $\cdot 3 \mathrm{I}_{2}$ complexes. ${ }^{14}$ On the other hand, the bent $\mathrm{I}_{5}{ }^{-}$ion in the $\left(\mathrm{CH}_{3}\right)_{4} \mathrm{~N}^{+} \mathrm{I}_{5}{ }^{-}$complex exhibits quite broad and split bands in the resonance Raman spectrum. ${ }^{14}$ In the PVAiodine complex, a sharp and strong band is observed at $164 \mathrm{~cm}^{-1}$, suggesting that the symmetric and linear $\mathrm{I}_{5}{ }^{-}$is formed. In the nylon 6-iodine complex, the band observed at $113 \mathrm{~cm}^{-1}$ was assigned to the $\mathrm{I}_{3}{ }^{-}$species because of the large change in the relative intensities of bands at 113 and $169 \mathrm{~cm}^{-1}$ with change in the sample history. In this case the ratio of the intensity at $108 \mathrm{~cm}^{-1}$ to that at $164 \mathrm{~cm}^{-1}$, evaluated from the peak areas, remained almost unchanged with the iodine concentration. The resonance Raman spectrum of iodine containing PVA films seemed to depend on the degree of polymerization DP. ${ }^{4}$ In the case of PVA of DP $=500$, the strong Raman band at $106 \mathrm{~cm}^{-1}$ was found to appear and as many overtones could be observed as the sixth for the excitation by $488.0 \mathrm{~nm}$ line of $\mathrm{Ar}^{+}$ion laser, while the scattering species was assigned to $\mathrm{I}_{3}{ }^{-}$, on the basis of the Raman data by Teitelbaum et al. ${ }^{5}$ However, in the case of PVA of DP $=2000$, the resonance Raman spectrum exhibited no band assignable to the $\mathrm{I}_{3}{ }^{-}$species. The difference between these Raman spectra may depend on the residual amount of acetyl groups.*

Anyway, PVA of DP $=2000$ was used in this study, and a combination band of the scatterings of 164 and $108 \mathrm{~cm}^{-1}$ was observed. Thus, we conclude that only the $\mathrm{I}_{5}{ }^{-}$species is formed in the PVA-iodine complex at this swollen system. Next, the reason for the red shift of $\lambda_{\max }$ with increasing $\mathrm{DH}$ was investigated. Generally, one may list the following three

* In the original manuscript we considered that the difference in the results of ref 4 and this work must be due only to differences in the degree of polymerization. One of the referees, however, kindly suggested that the difference might be also due to that in the residual amounts of acetyl groups, since in ref 4 , the commerical sample was used without further saponification, while in this work, the sample was further saponified, and very small amounts of acetyl groups possibly have great influence on the complexation. His suggestion is considered to be reasonable enough to take into consideration. 
possibilities for the problem: (I) the increase in the number of atoms in a polyiodine, (II) the increase in the fraction of the species with larger number of atoms, (III) some other changes in the structure of the complex than that in the number of iodine atoms, i.e., the change in the surroundings of the polyiodine chain. The results on the resonance Raman spectra showed that the second possibility is not this case, although we adopted this explanation in our previous paper. ${ }^{6}$ Thus we should say that our explanation in ref 6 ought to be withdrawn.

Swollen PVA films of $\mathrm{DH}=0.87$ and 0.47 soaked in an iodine solution of $1 \times 10^{-3} \mathrm{~mol}$ $1^{-1}$ for 24 hours, had $\lambda_{\text {max }}$ at 614 and $532 \mathrm{~nm}$ in the visible absorption spectra, respectively. The resonance Raman spectra of these specimens obtained with the $514.5 \mathrm{~nm}$ line of the $\mathrm{Ar}^{+}$ion laser and the $600.0 \mathrm{~nm}$ line of a dye laser are shown in Figures 2 and 3, respectively. It should be noted that all these spectra are essentially identical, i.e., these spectra are hardly affected by changes in DH of PVA films and by the wave length of excitation. This indicates that the scattering species are essentially identical even for specimens with different values of $\lambda_{\max }$. If the iodine in the PVA-iodine complex takes a form other than linear $\mathrm{I}_{5}{ }^{-}$, one would expect some differences in the spectra.

The change in the wavelength if excitation only causes a slight shift in the frequency of transition from 164 to $160 \mathrm{~cm}^{-1}$ and a sharpening of the peak at $160 \mathrm{~cm}^{-1}$ for both specimens, indicating that the scattering species are essentially identical for these specimens. Therefore, it is concluded that the shift changes in the surroundings of the $\mathrm{I}_{5}{ }^{-}$ polyiodine chain.

The polarized Raman scattering of a specimen dried after being extended in a dilute iodine solution was measured to study the orientation of the polyiodine chain. Figure 4 shows the polarized resonance Raman spectra of an iodinated uniaxially oriented PVA

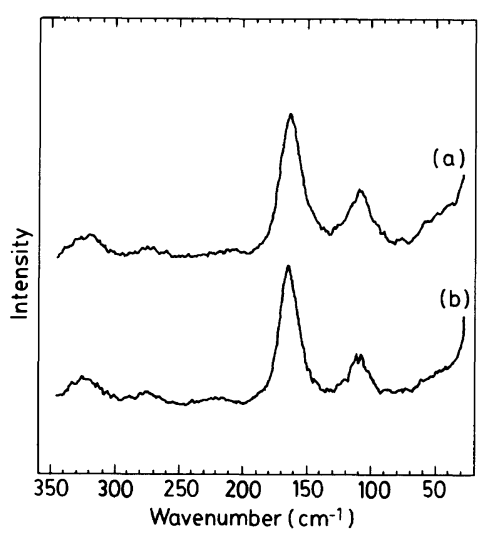

Figure 2. The resonance Raman spectra ( $v_{0} 514.5 \mathrm{~nm}$ ) of swollen PVA films on complexation of (a) $\mathrm{DH}=0.87$; (b) $\mathrm{DH}=0.47$.

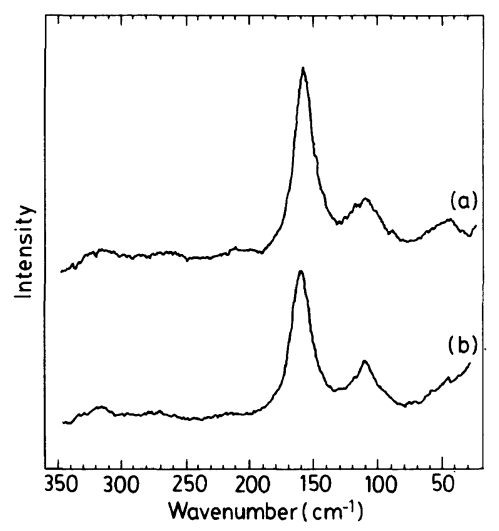

Figure 3. The resonance Raman spectra ( $\left.v_{0} 600.0 \mathrm{~nm}\right)$ of swollen PVA films on complexation of (a) $\mathrm{DH}=0.87$; (b) $\mathrm{DH}=0.47$.

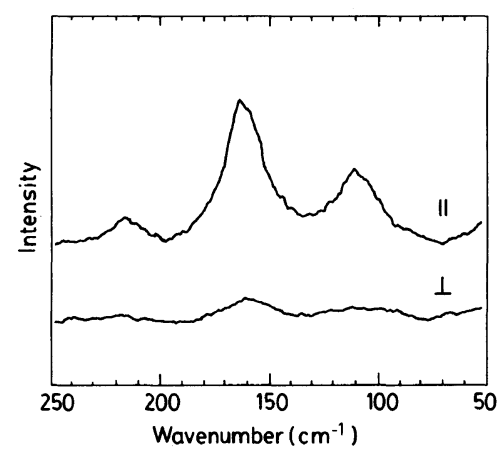

Figure 4. Polarized resonance Raman spectra of iodinated, uniaxially oriented PVA film. The polarizations with respect to the draw direction are shown in this figure. 
film. Two major transitions at 108 and $164 \mathrm{~cm}^{-1}$ were observed. The scattering intensity in the polarization along the draw direction is much more intense than that in the polarization normal to the draw direction. This indicates that $\mathrm{I}_{5}{ }^{-}$species is highly oriented parallel to the draw direction.

The number of iodine atoms in a polyiodine chain was also estimated from the width of the $\mathrm{X}$-ray diffraction meridional peak of the oriented specimen, which arises from the linear iodine lattice. ${ }^{1}$ In this case, the meridional peak appeared at $2 \theta=28.8^{\circ}$, showing that the iodine atoms form a linear lattice of $3.1 \AA$ in the direction of molecular orientation. The Laue function for a linear lattice consisting of $N$ atoms is given by

$$
L^{2}(S)=(\sin N \pi S \cdot C / \sin \pi S \cdot C)^{2}
$$

where $S$ is the scattering vector, $C$ is the lattice vector whose length is $3.1 \AA$ in this case. The width of the function was graphically estimated as a function of $N$ to be compared with the experimentally estimated values. In the experimental estimation of this peak width, the instrumental broadening was corrected using silicon powder. The number of iodine atoms thus obtained is shown as a function of $\lambda_{\max }$ in Figure 5. The estimated number of iodine atoms at each $\lambda_{\max }$ gives about 9 , which is certainly too large for $\mathrm{I}_{5}{ }^{-}$. It should be remarked that the width of the profile tends to increase slightly with increasing $\lambda_{\max }$, and that the value of $N$ estimated from the width increases between 9 and 10, as shown in Figure 5. Originally, $N$ must be an integral number. However, it may be possible for $N$ to be more than five if the $\mathrm{I}_{5}{ }^{-}$species can aggregate in the complex, having a phase correlation between (or among) them, although this possibility has not yet been checked. In the case of iodine-doped polyacetylene, the number of iodine atoms estimated by $\mathrm{X}$-ray diffraction was also much larger than that expected from other reliable techniques, as in this case. ${ }^{17}$ The reason why such large values are estimated by

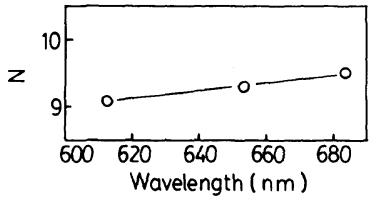

Figure 5. The number of iodine atoms as a function of $\lambda_{\max }$ of extended PVA film by a factor of 2.5 in the iodine solution of $3 \times 10^{-3} \mathrm{moll}^{-1}$.

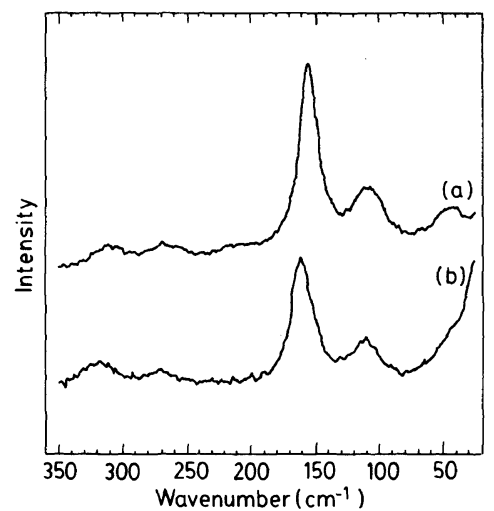

Figure 6. Exciting frequency $\left(v_{0}\right)$ dependence of the resonance Raman spectra of swollen PVA film on enhanced complexation by an addition of boric acid $\left(\mathrm{I}_{2}\right.$ $2 \mathrm{KI}, 5 \times 10^{-4} \mathrm{moll}^{-1} ; \mathrm{B}(\mathrm{OH})_{3}, 5 \times 10^{-1} \mathrm{moll}^{-1}$ ): (a) $600.0 \mathrm{~nm}$; (b) $514.5 \mathrm{~nm}$.

X-ray diffraction method should be studied further.

The resonance Raman spectra of the PVA film soaked in an iodine solution added with boric acid, having $\lambda_{\max }$ at $650 \mathrm{~nm}$ obtained with the $514.5 \mathrm{~nm}$ and $600.0 \mathrm{~nm}$ lines of the $\mathrm{Ar}^{+}$ion and dye lasers are shown in Figure 6. There are no observable differences in their spectra. This also implies that the shift of $\lambda_{\max }$ caused by the addition of boric acid is due to the surroundings in the polyiodine chain.

A high-resolution solid state ${ }^{13} \mathrm{C}$ NMR by the combined techniques (CP/MAS) was also used to study the structure of PVA chains in the complex. The specimens were prepared by soaking PVA films in iodine solutions of $2 \times 10^{-3}$ and $8 \times 10^{-2} \mathrm{~mol} \mathrm{l}^{-1}$, followed by drying in air. The CP/MAS spectra of these specimens and of an untreated PVA film are shown in Figure 7. The relative intensity of the 


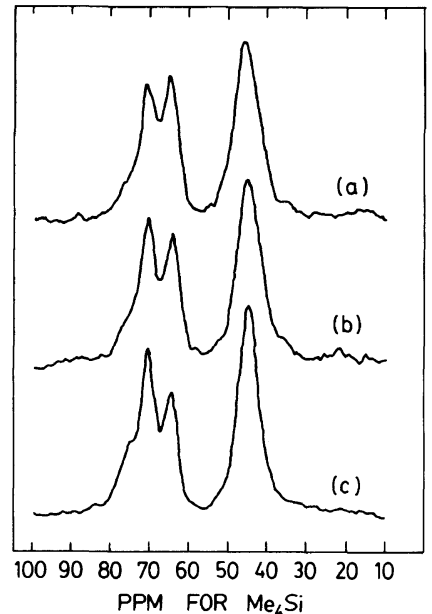

Figure 7. ${ }^{13} \mathrm{C} \mathrm{CP} / \mathrm{MAS}$ spectra of PVA films soaked in (a) water; (b) iodine solution of $2 \times 10^{-3} \mathrm{moll}^{-1}$; (c) iodine solution of $8 \times 10^{-2} \mathrm{moll}^{-1}$.

peak at $65 \mathrm{ppm}$ decreases with increasing concentration of the iodine solution, i.e., the increase in the amount of the complex. The decrease is considered to be attributable to the breakage of intermolecular hydrogen bonds. ${ }^{12}$ This indicates that the PVA segments participating in the complexation, which is supposed to surround a polyiodine chain, lose their ability to form hydrogen bonds with the neighboring segments. This change in hydrogenbonding of PVA segments will be discussed further by IR spectrum.

It is well known that the broad band at $3340 \mathrm{~cm}^{-1}$ observed in the IR spectrum of PVA is assigned to the $v(\mathrm{OH})$ mode, ${ }^{18}$ and that this absorption of frequency indicates the existence of an intermolecular type of hydrogen bonding. Then, we investigated the change in the structure of PVA on complexation by IR analysis. Figure 8(a) shows the infrared spectra for the region of 2800 $3800 \mathrm{~cm}^{-1}$ of PVA films soaked at various concentrations of iodine. The broad band at $3340 \mathrm{~cm}^{-1}$ observed in the spectra slightly shifts to a higher frequency with increasing iodine concentration. To clarify the change,
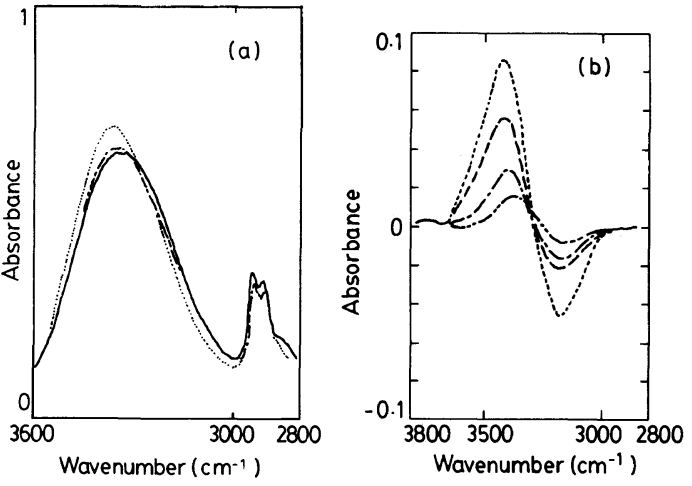

Figure 8. (a) The infrared spectra of iodine-sorbed PVA film: (-) untreated; (---) $6 \times 10^{-2} \mathrm{moll}^{-1}$; (-----) $1 \times 10^{-1} \mathrm{moll}^{-1}$. (b) The difference spectra of iodine-sorbed PVA film: (---) $2 \times 10^{-2} \mathrm{moll}^{-1}$; (---) $6 \times 10^{-2} \mathrm{moll}^{-1}$; (---) $8 \times 10^{-2} \mathrm{moll}^{-1}$; (-----) $1 \times 10^{-1}$ $\mathrm{moll}^{-1}$.

the difference between the spectra of a PVA film which sorbed a given amount of iodine and of the pure PVA film is shown in Figure 8(b). A systematic change is observed in the region of $2800-3800 \mathrm{~cm}^{-1}$ on the IR spectrum with increasing iodine concentration in the soaking solution. The absorbance in the region of $2900-3300 \mathrm{~cm}^{-1}$ decreases with increasing iodine concentration, while the absorbance in the region of $3300-3700 \mathrm{~cm}^{-1}$ increases. However, the magnitude of this change is small, as seen in Figure 8(a). It has been shown that certain dihydroxy compounds possess two $\mathrm{OH}$ stretching bands and that the higher and lower frequency bands are due to the intramolecular and the intermolecular hydrogen bonds ${ }^{19}$ respectively. These results indicate that the intermolecular hydrogen bonds are broken by complexation, resulting in the increase of the intramolecular hydrogen bond. This and the results on the resonance Raman seem to support an aggregation model in which the polyiodine is covered by a flux of some PVA chains.

Figure 9 shows small angle $\mathrm{X}$-ray scattering profiles of swollen PVA films of $\mathrm{DH}=0.60$ soaked in iodine solutions of $0,5 \times 10^{-3}$, $5 \times 10^{-2} \mathrm{~mol} \mathrm{l}^{-1}$. The scattering intensity in- 


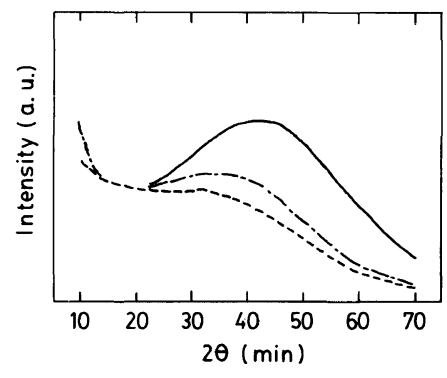

Figure 9. Change in small angle $\mathrm{X}$-ray scattering profile of the swollen PVA film on complexation: (---) untreated; (--) $5 \times 10^{-3} \mathrm{moll}^{-1} ;(-) 5 \times 10^{-2}$ moll $1^{-1}$.

Table I. Change in the long period of the swollen PVA film on complexation

\begin{tabular}{cc}
\hline Iodine concentration & Long period \\
moll $^{-1}$ & $\AA$ \\
\hline 0 & 151 \\
$5 \times 10^{-3}$ & 139 \\
$5 \times 10^{-2}$ & 126 \\
\hline
\end{tabular}

creases with increasing iodine concentration, which is considered due to the increase in the density difference between the PVA crystallite and iodine-sorbed amorphous PVA. The long period of each specimen observed in Figure 9 is shown in Table I. It decreases with increasing iodine concentration, and the ratio of the long period of the specimen soaked in the $5 \times 10^{-2} \mathrm{~mol} \mathrm{l}^{-1}$ solution to that of the unsoaked specimen was 0.83 in this specimen of $\mathrm{DH}=0.60$.

Figure 10 shows changes of the volume, Young's modulus, long period and weight of the PVA film of $\mathrm{DH}=0.70$ during soaking in the iodine solution of $5 \times 10^{-2} \mathrm{~mol} \mathrm{l}^{-1}$. The weight of the PVA film increased rapidly by iodine sorption during the first several minutes and then started to decrease. It is considered that this decrease in weight is due to the release of water. The changes of the long period and volume took place rapidly and ended in an hour, while the change of Young's modulus took place much slower and lasted for six or

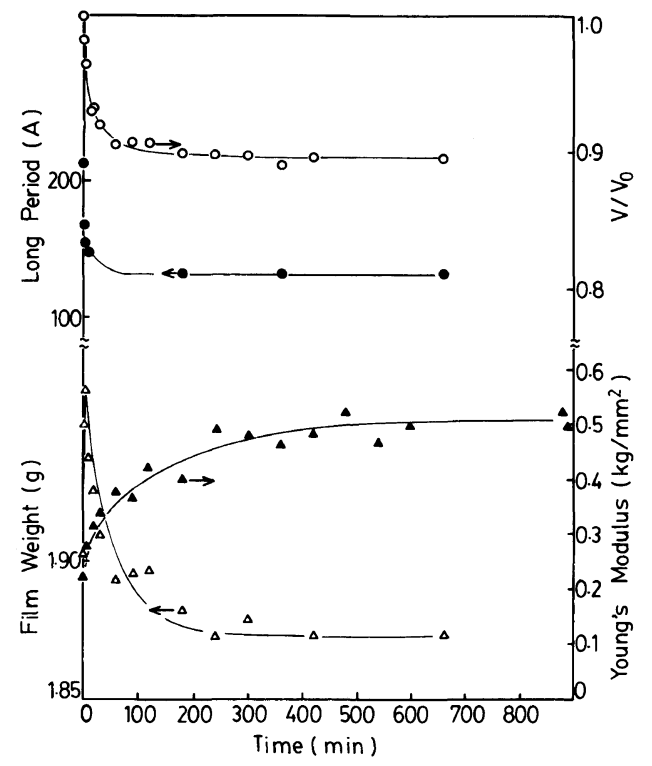

Figure 10. The time dependency of volume, Young's modulus, long period and weight of the swollen PVA film during soaking in the iodine solution.

seven hours. Kojima et al. ${ }^{7}$ considered that the contraction of a film in an iodine solution was due to the additional formation of networks induced by PVA-iodine complexes. However, we would like to assume from the fast changes in the volume and the weight in an iodine solution that the contraction of the film is due to the release of water out of the membranes induced by iodine sorption. The ratios of the volume in the iodine solution to that in water was 0.90 , while that of the long period was 0.62 , indicating that the contraction of the long period is much larger than that of the volume. This implies that the contraction is induced in the amorphous chain networks formed by tie chains, both ends of which are fixed at the interfaces of the crystals stacked in series along the long period, and also suggests a high reliability of our proposal of the double network structure in a previous paper. ${ }^{7}$

\section{CONCLUSION}

The PVA-iodine complex at the swollen 
state is formed so that the polyiodine chain $\left(\mathrm{I}_{5}{ }^{-}\right.$species) may be surrounded by several extended PVA segments. The shift of $\lambda_{\text {max }}$, caused by $\mathrm{DH}$, the addition of boric acid and the extension of an iodine-sorbed PVA film, is due to the change in the surroundings of the polyiodine chain. Iodine sorption of PVA films leads to the release of water and contraction in the amorphous chain network, resulting in the contraction of the PVA film.

Acknowledgements. We are greatly indebted to Professor Shiro Maeda and Dr. Yukio Adachi of Research Laboratory of Resources Utilization, Tokyo Institute of Technology for providing the Laser-Raman spectrometer and for helpful discussions on the interpretation of Raman spectra.

\section{REFERENCES}

1. C. D. West, J. Chem. Phys., 15, 689 (1947).

2. M. Haisa and H. Itami, J. Phys. Chem., 61, 817 (1957).

3. M. E. Heyde, L. Rimai, R. G. Kilponen, and D. Gill, J. Am. Chem. Soc., 94, 5222 (1972).
4. F. Inagaki, I. Harada, T. Shimanouchi, and M. Tasumi, Bull. Chem. Soc. Jpn., 45, 3384 (1972).

5. R. C. Teitelbaum, S. L. Ruby, and T. J. Marks, J. Am. Chem. Soc., 102, 3322 (1980).

6. Y. Oishi and K. Miyasaka, Polym. J., 18, 307 (1986).

7. Y. Kojima, K. Furuhata, and K. Miyasaka, J. Appl. Polym. Sci., 30, 1617 (1985).

8. M. M. Zwich, J. Appl. Polym. Sci., 9, 2393 (1965).

9. R. E. Rundle, J. F. Foster, and R. R. Baldwin, J. Am. Chem. Soc., 66, 2116 (1944).

10. L. G. Tebelev, G. F. Mikul'skii, YE. P. Korchagina, and S. A. Glikman, Vysokomol. Soedin, Ser. A, 7, 1231 (1965).

11. Y. Oishi and K. Miyasaka, Polym. J., 19, 331 (1987).

12. T. Terao, S. Maeda, and A. Saika, Macromolecules, 16, 1535 (1983).

13. O. Kratky, G. Porod, and L. Kahove, $Z$. Electrochem., 55, 53 (1951).

14. L. R. Sarles and R. M. Cottos, Phys. Rev., 111, 853 (1958).

15. E. R. Andrew, Int. Rev. Phys. Chem., 1, 195 (1981).

16. V. J. Bartuska and G. E. Maciel, J. Magn. Reson., 42, 312 (1981).

17. T. Danno, K. Miyasaka, and K. Ishikawa, J. Polym. Sci. Phys., 21, 1527 (1983).

18. For example, A. Elliot, E. J. Ambrose, and R. B. Temple, J. Chem. Phys., 16, 877 (1948).

19. S. Murahashi, H. Yuki, T. Sano, U. Yonemura, H. Tadokoro, and Y. Chatani, J. Polym. Sci., 62, S77 (1962); M. Matsumoto and K. Imai, Kobunshi Kagaku, 15, 160 (1958). 